\title{
Multidimensional analysis and mobility: special issue in homage to Tony Atkinson
}

\section{Markus Jäntti ${ }^{1} \cdot$ Dirk Van de gaer ${ }^{2,3}$}

Published online: 18 March 2019

(C) Springer Science+Business Media, LLC, part of Springer Nature 2019

This third and final special issue of the Journal of Economic Inequality published in honour of Sir Anthony "Tony" Atkinson focuses on multi-dimensional aspects of welfare and poverty measurement, and mobility. Tony's main concerns were both conceptual and empirical. Conceptually, he established results that can be used to reach consensus in contexts where people have different value judgments. Empirically, he advocated intelligent use of data, considering what effect their shortcomings had on the subject matter at hand as well as if and how such shortcomings could be overcome.

As early as 1980, Tony devoted a paper to the relationship between inequality of outcome and inequality of opportunity (Atkinson 1980). One of the questions put forward in the introduction of that paper concerns the relation beteen inequality of opportunity and inequality of outcome. He concluded "... there is no straightforward link between inequality of opportunity and inequality of results ..." (p.76). Alain Trannoy shows, in the context of a particular model, that there is a tight relations between both concepts.

Alain Trannoy studies liberal equality of opportunity in a Mirrleesian setting with, at the one hand effort and at the other hand talent, the only circumstance. Both are unobserved by the government. He uses the Mirrleesian framework, such that the relevant outcomes are individual utilities and everyone has the same preferences. In this set-up, the principle of natural reward requires that those with the same talents pay the same net taxes. He shows that this is satisfied automatically with an income tax schedule that only depends on gross income. The principle of compensation requires that for the same effort all attain the same indifference curve irrespective of their innate talent. He shows this implies that a Rawlsian social welfare function should be maximized. Thereby he obtains the surprising result that in this private information setting where everyone has the same preferences, liberal equality of opportunity coincides with maximizing the utility of the worst-off.

Markus Jäntti

markus.jantti@sofi.su.se

Dirk Van de gaer

Dirk.Vandegaer@ugent.be

1 Swedish Institute for Social Research, Stockholm University, Stockholm, Sweden

2 Department of Economics, Ghent University, Gent, Belgium

3 CORE, Université Catholique de Louvain, Louvain-la-Neuve, Belgium 
Together with Bourguignon (Atkinson and Bourguignon 1982), Tony performed pathbreaking work on multidimensional inequality and welfare measurement. They were concerned with situations where there is no unanimous agreement on the extent of substitutability (or complementarity) between different dimensions. They apply the same trade-offs between the dimensions to everyone's goods vector. Tony also contributed to the measurement of one-dimensional poverty (Atkinson 1987). His focus was on cases when there is no unanimous agreement on the level of the poverty line and everyone with an income below the poverty line is identified as poor. In the standard multidimensional setting, a poverty line is determined for every dimension and all individuals with the same goods vector will be classified as either poor or non-poor (see, e.g., Aaberge and Brandolini 2015). Koen Decancq, Marc Fleurbaey and François Maniquet provide new answers to the measurement of multidimensional poverty, based on individuals' own trade-offs between different dimensions.

Their core idea, to hold individuals responsible for their preferences, is one of the leading responsibility principles in equality of opportunity theories. From this principle, it follows that individuals' preferences should be respected in the measurement of multidimensional poverty. Individuals identify themselves as poor by comparing their goods vector to the multidimensional poverty-line vector. For every individual, the tradeoff between different dimensions in his good bundle, and the severity of his poverty are based on his own preferences. They characterize an additively separable poverty measure for which TIP-like dominance in the spirit of Jenkins and Lambert (1997) can be applied. The approach is implemented using Russian survey data (RLMS-HSE). Compared to standard approaches, different people are identified as poor.

A good example of Tony's approach to empirical work is the study of intergenerational income mobility in Great Britain (see e.g. Atkinson et al. 1983) that was based on following up and surveying offspring of families included in Seebohm Rowntree's survey of poor families in York (Rowntree and Lavers 1951). It turned out that Rowntree had left roughly a quarter of the more well-todo families un-surveyed, so there were no offspring to followup. This in turn created problems for analysts aiming to estimate, from such censored data, statistics that apply to the overall population (i.e., including the well-todo). One statistic of interest is the mobility matrix, which, when based on groups by quantiles, e.g. quartiles, is bistochastic - i.e., all rows and columns sum to one. Since the omitted households consisted of roughly the top fourth, the missing row in the mobility matrix could be worked out from the condition that each column must sum to one.

In work that aims to enrich our understanding of mobility based on incomplete data, Dang and Lanjouw (2013; DL) and Dang et al. (2014; DLLM) develop methods that allow researchers to study intra-generational (income) poverty mobility and persistence in settings in which repeated observations of the same individuals are not only incomplete but entirely lacking. DLLM suggested two "bounds approaches", a non-parametric one that relies on the empirical residuals of an income model (assuming both independence across years for maximum mobility and perfect correlation for minimum mobility) and a parametric one that relies on assumed bivariate log normality as well as imputed upper and lower correlations. DL further propose a way to estimate the cross-year correlation using pseudo panels. Both the non-parametric and the DLLM/DL parametric methods allow researchers to calculate mobility statistics, with DLLM providing bounds and DL providing point estimates. They extensively validate their methods by comparing their methods' results to actual estimates in settings where repeated observations are available and find, in general, their methods to work well. 
Noting that most validations are conducted in the context of low- or middle-income countries, Nicolas Hérault and Stephen Jenkins set out to examine how these methods fare in two rich countries with long-running and high-quality panel datasets, namely Australia (HILDA) and Britain (BHPS). Such a comparison is timely, not least as the DL and DLLM methods are frequently being used. After presenting the DL and DLLM methods, Hérault and Jenkins proceed to examine how the methods perform in multiple waves of the Australian and British data relative to income mobility estimates based on actual repeated measurement for the same individuals. They setup their analysis such that a substantial number of variations of the study population and methods can be succinctly analyzed; in the main analysis, they examine households in which the head is either 25-75 ("leading case") or 25-55 years old.

Comparing the estimated and actual correlation of consecutive income observations across the whole period for the two groups defined by head's age, they find especially within the narrower 25-55 year old population that the DLLM correlation can depart quite substantially from the micro-data-based estimate. The poverty persistence probability (of being poor in both years) appears to be captured reasonably accurately in the leading case, but the other joint poverty probabilities less so. The parametric bounds mostly appear relatively wide but for the most part contain the $95 \%$ confidence interval of the micro-data-based "true" estimate. They then provide a number of variations of the leading case. The overall conclusion is that the DL method performs less well in the Australian and British data than in earlier validations using low- and middle-income country data.

An important but often implicit assumption in models of intergenerational income persistence is that of "steady-state", e.g., that the underlying parameters are at their long-run stable values (Becker and Tomes 1986; Solon 2004). In research on intergenerational socioeconomic links before the 1980s (e.g. Conlisk 1974), the assumption was often invoked to allow for the substitution of parameters that could not be estimated in a dataset from other sources. Atkinson and Jenkins (1984) explore some of the consequences of steady-state assumptions in the context of such models.

Martin Nybom and Jan Stuhler take as their point of departure a variant of the structural statistical model linking education and income across parents and children that Atkinson and Jenkins (1984) examined, and explore the consequences of imposing steady-state assumptions for research on intergenerational persistence. A useful implication of the steady-state assumption is that all cross-sectional variances are constant. The authors show that a simple steady-state estimator of intergenerational income persistence can be constructed based on estimated correlations of offspring income and education with parental education information you often have in cross-sectional data, whereas parental income is often not present. Using data for Sweden, they demonstrate the steady-state estimator to be grossly biased, not least as the variances are far from steady-state.

Atkinson and Jenkins (1984) cautioned researchers to be skeptical of steady-state assumptions or, at the very least, to be very careful in their use and the interpretation of results obtained using them. Nybom and Stuhler go on to discuss their implications in several other settings, such as in so-called two-sample instrumental variable estimates of mobility (e.g. Björklund and Jäntti 1997), multigenerational and "latent" transmission (e.g. Lindahl et al. 2015; Clark 2014), as well as the interpretation of changes in intergenerational mobility. What characterizes all of their analysis is the careful detail they pay to what can not but also what can be said based on actual data in light of the assumptions that are imposed. For instance, it turns out that instead of using "vertical" (across-generation) moments, researchers can rely on "horizontal" (within-generation) moments to overcome some of the problems associated with steady-state assumptions - i.e., using data for siblings in the two-generation or cousins in the three-generation case. They also point out that the 
transitional dynamics of intergenerational income persistence can be surprisingly complicated and, in particular, non-monotonic, for several generations following an initial shock, an observation that puts simple questions about "trends" in intergenerational mobility in a dubious light.

In this special issue researchers pursue topics arising from Tony's work on inequality and mobility in a longitudinal setting. This is, at the one hand, because many important conceptual, welfare-economic questions remain, if not unresolved, at least lacking in clarity, and, at the other hand, because the implications of data imperfections and other problems that researchers encounter when applying methods to data are incompletely understood. In publishing these articles in this third and final issue in honour of Sir Tony Atkinson, the Journal hopes to encourage researchers to continue to pursue answers to these questions raised and analyzed by Tony.

\section{References}

Aaberge, R., Brandolini, A.: Multidimensional poverty and inequality. In: Atkinson, A.B., Bourguignon, F. (eds.) Handbook of income distribution, vol 2A, North Holland. Elsevier, Amsterdam (2015)

Atkinson, A.B.: Income distribution and inequality of opportunity. IHS J. 3(series A), 65-80 (1980)

Atkinson, A.B., Bourguignon, F.: The comparison of multi-dimensioned distributions of economic status. Rev. Econ. Stud. 49, 183-201 (1982)

Atkinson, A.B.: On the measurement of poverty. Econometrica 55, 749-764 (1987)

Atkinson, A.B., Jenkins, S.P.: The Steady-State assumption and the estimation of distributional and related models. J. Hum. Resour. 19(3), 358-76 (1984)

Atkinson, A.B., Maynard, A.K., Trinder, C.G.: Parents and children: incomes in two generations. Heinemann Educational Books, London (1983)

Becker, G., Tomes, N.: Human capital and the rise and fall of families. J. Labor Econ. 4(3), S1-39 (1986)

Björklund, A., Jäntti, M.: Intergenerational income mobility in Sweden compared to the United States. Amer. Econ. Rev. 87(4), 1009-18 (1997)

Clark, G.: The son also rises: surnames and the history of social mobility. Princeton University Press, Princeton (2014)

Conlisk, J.: Can equalization of opportunity reduce social mobility? Amer. Econ. Rev. 64(1), 80-90 (1974)

Dang, H.-A., Lanjouw, P.: Measuring poverty dynamics with synthetic panels based on Cross-Sections. Policy research working paper 6504 The World Bank (2013)

Dang, H.-A., Lanjouw, P., Luoto, L., D McKenzie, D.: Using repeated cross-sections to explore movements into and out of poverty. J. Dev. Econ. 107, 112-18 (2014)

Jenkins, S., Lambert, P.J.: Three I's of poverty curves, with an analysis of UK poverty trends. Oxf. Econ. Pap. 49, 317-327 (1997)

Lindahl, M., Palme, M., Sandgren Massih, S., Sjögren, A.: Long-term intergenerational persistence of human capital: an empirical analysis of four generations. J. Hum. Resour. 50(1), 1-33 (2015)

Rowntree, S., Lavers, G.R.: Poverty and the Welfare State. Longman Green (1951)

Solon, G.: A model of intergenerational mobility variation over time and place. In: Corak, M. (ed.) Generational Income Mobility in North America and Europe, chapter 2, pp. 38-47. Cambridge University Press, Cambridge (2004)

Publisher's note Springer Nature remains neutral with regard to jurisdictional claims in published maps and institutional affiliations. 